\title{
HERNEKÄÄRIÄISEN (GRAPHOLITHA NIGRICANA STEPH.) PELTOHERNEELLE AIHEUTTAMISTA VAHINGOISTA.
}

\author{
OIVA INKILÄ. \\ Maatalouskoelaitoksen kasvinjalostusosasto, Jokioinen.
}

Saapunut 10. 4. 1948 .

Eräs herneviljelystemme pahimpia ja vaikeimmin torjuttavia tuhohyönteisiä on hernekääriäisen (Grapholitha nigricana STEPH.) toukka eli ns. "hernemato". Kyseinen hyönteinen on Tortricidae-heimoon kuuluva pieni perhonen (siipikärkiväli $14-15 \mathrm{~mm}$ ). Sen etusiivet ovat tuhkanharmaat. Siipien etureunassa on lyhyitä viistoon kulkevia valkeita ja tummia viiruja. Lähellä siipien kärkiä on laikku, jossa on mustia täpliä sekä kellahtavia viivoja. Takasiivet ovat tummanruskeat. Toukka, joka täysinkehittyneenä on $7-8 \mathrm{~mm}$ :n pituinen, on väriltään kellertävä tai vaalean vihertävä. Sen pää ja niskakilpi ovat mustat tai ruskeat. Ruumiin nivelissä on useita sukasilla varustettuja tummia käsniä. Kotelo on 8-10 mm:n pituinen, kellertävän ruskea. Perhonen on liikkeellä herneen kukintaaikana heti auringonlaskun jälkeen. Naaras laskee munansa herneiden lehdille, kukille tai nuorten palonalkujen verholehdille, tavallisesti yksitellen, harvemmin 2-3 yhdessä. Toukka kehittyy munasta runsaan viikon kuluttua. Se kaivautuu nuoreen palkoon ja alkaa syödä siemeniä, nakertaen niihin koloja ja käytäviä. Noin kolmen viikon kuluttua toukka on kehittynyt täysimittaiseksi. Se jättää silloin palon ja kaivautuu maahan n. 3-4 cm:n syvyyteen sekä koteloituu. Täysikasvuiseksi kehittyminen tapahtuu seuraavana keväänä.

Kuten alussa huomautettiin, hernekääriäinen on varsin yleinen tuhojen aiheuttaja herneviljelyksillämme. Se on jo vanhastaan tunnettu maassamme, ja on se levinnyt yli koko herneenviljelysalueemme aina Suomussalmen seuduille asti. Pahimmat tuhonsa se useimmiten kuitenkin on aiheuttanut maamme varsinaisella herneenviljelysalueella nimenomaan Ahvenanmaalla ja lounais-Suomessa (HukKinen, Listo ja VAPpula 4; VAppula 12, 13 ja 14). Tuhojen laajuus on vaihdellut eri vuosina varsin suuresti. Joinakin vuosina on hernekääriäinen esiintynyt laajoilla alueilla erittäin tuhoisana, kuten esim. vuosina 1914 ja 1915, (HukKINEN 3). Toisinaan sen runsas esiintyminen on ollut vain paikallista. Niinpä Linnaniemen (5) mukaan hernekääriäisen tuhot vuosina 1918-1923 olivat koko maassa hämmäs- 
tyttävän vähäiset. Vuosina 1921-1922 se kuitenkin esiintyi Tammistossa niin tuhoisana, että miltei jokainen palko oli vioitettu (SAULI 10).

Hernekääriäisen tuhojen torjuminen on erittäin vaikeaa, koska toukka miltei koko kehityskautensa on suljetussa palossa. Toistaiseksi ei ole tunnettu mitään täysin tehokasta keinoa tuhojen ehkäisemiseksi. Ruotsissa viime aikoina suoritetut tutkimukset (SchWAN 11, 12) ovat kuitenkin osoittaneet, että kohdistamalla torjuntatoimenpiteet muna-asteeseen sekä vastikään kehittyneeseen nuoreen toukkaan, voidaan nikotiini- ja DDT-ruiskutuksilla huomattavasti vähentää, joskaan ei kokonaan torjua, hernekääriäisen aiheuttamia tuhoja. Ruiskutuksia on tällöin kuitenkin suoritettava herneen kukinta-aikana useampia säännöllisin väliajoin, jotta tulos olisi tyydyttävä, koska herneen kukkiminen tapahtuu asteettain ja perhonen suorittaa munintansa pitkähkön ajan kuluessa.

Jossain määrin hernekääriäisen tuhoja mainitaan voitavan vähentää eräin viljelyksellisin toimenpitein (Tullgren 13; Tunblad 14; Schwan 11). Kyntämällä maa syvään heti korjuun jälkeen sekä muilla kunnollisesti suoritetuilla muokkaustoimenpiteillä voitaneen talvehtimaan asettuneita toukkia jonkin verran hävittää. Vuoroviljelyksellä sekä sijoittamalla herneviljelys mahdollisimman kauaksi edellisen vuoden kasvupaikasta on myös havaittu voitavan vähentää kääriäistuhoja. Käytännöllisen kokemuksen perusteella sekä eräiden mm. Saksassa suoritettujen tutkimusten mukaan (ref. SchwaN 11) on tultu siihen käsitykseen, että viljelemällä hernettä jonkin kevätviljan seassa, ovat hernekääriäisen tuhot vähäisemmät kuin puhtailla herneviljelyksillä. Herne-kauran viljelyn vaikutuksesta hernekääriäisen esiintymiseen ovat ERICsson ja Genchel (2) Ruotsissa vuonna 1946 suorittamissaan tutkimuksissa kuitenkin tulleet aivan päinvastaiseen tulokseen. Tehokkaana torjuntakeinona joukkotuhojen esiintyessä mainitsee SAULI (10) herneen niittämisen vihantana ja syöttämisen eläimille, jolloin toukat tuhoutuvat. Näin menetellen saatiin hernekääriäisen tuhoisa esiintyminen loppumaan Tammistossa vuonna 1922 .

Jokioisissa vv. $1944-1947$ suoritetut tutkimukset.

\section{Tutkimusaineisto ja -menetelmät.}

Tutkimusaineisto saatiin peltoherneen vertailevista kenttäkokeista. Kokeissa oli mukana pääasiassa osaston omia linja-asteella olevia jalosteita sekä eräitä nimellisiä lajikkeita. Tutkittujen lajikkeiden lukumäärät eri vuosina on esitetty taulukossa 1. Vuonna 1944 oli tutkimuksissa mukana 32, vuonna 1945 21, vuonna 194671 sekä vuonna 194764 lajiketta ja linjaa. Hernekääriäisen toukan aiheuttaman vioituksen suuruus määritettiin siten, että puinnin jälkeen puhdistamattomasta siemensadosta otettiin $1 \mathrm{~kg}: n$ suuruinen (eräissä tapauksissa pienempi) näyte, josta käsin lajitellen eroitettiin vioittuneet herneet sekä määritettiin näiden paino ja prosenttinen osuus sadossa. Lisäksi määritettiin vioittuneiden herneiden 
1000 siemenen painot eri lajikkeilla. ${ }^{1}$ Tuntien terveiden herneiden vastaavat painot, voitiin laskea se suoranainen sadonvähennys, joka toukkien syönnistä oli aiheutunut. Koska koekentällä tehtiin myös havainnot eri lajikkeiden kukkimisen alkamisesta ja päättymisestä sekä tuleentumisesta, voidaan selvitellä näiden seikkojen vaikutusta tuhojen suuruuteen.

\section{Sä̈̈suhteet.}

Koevuosien sääsuhteita selostettaessa kiinnitetään päähuomio kasvukausien "aikaisuuteen» sekä kevään ja keskikesän, nimenomaan herneen kukinta-ajan sääsuhteisiin, koska näillä epäilemättä on tärkeä merkitys hernekääriäisen kehitykselle.

Vuonna 1944 oli kasvukauden alkupuoli viileä ja melko runsassateinen. Herneen kylvö tapahtui verraten myöhään $(27 / V)$. Herneen kukinta eri lajikkeilla alkoi 7-16/VII. Kukinnan aikana ja sen alkaessa vallitsi melko lämmin, mutta runsassateinen sää. Vuonna 1945 oli kasvukauden alkupuoli samoin kuin edellisenäkin vuonna viileähkö, mutta sadesuhteiltaan lähes normaali. Herneen kylvö tapahtui kuitenkin aikaisemmin kuin edellisenä vuonna eli 16/V. Herneen kukinta eri lajikkeilla alkoi 9-14/VII eli samoihin aikoihin kuin edellisenä vuonna. Heinäkuu oli melko lämmin. Kuukauden alku oli vähäsateinen, mutta loppupuoli sensijaan varsin runsassateinen. Vuonna 1946 oli alkukesä kohtalaisen viileä ja melko sateinen. Herneen kylvö tapahtui verraten myöhään $(25 / \mathrm{V})$. Keskikesä, siis myös herneen kukinta-aika, joka alkoi $7-12 / \mathrm{VII}$, oli varsin lämmin ja poutainen. Näin ollen se oli erittäin edullinen useiden tuhohyönteisten kehitykselle. Vuonna 1947 oli kasvukauden alkupuoli melko lämmin ja verraten vähäsateinen. Herneen kylvö tapahtui $17 / \mathrm{V}$ ja kukinta alkoi $29 / \mathrm{VI}-4 / \mathrm{VII}$ eli jonkin verran aikaisemmin kuin edellisinä vuosina. Heinäkuun alkupuoli siis herneen kukinta-aika oli melko lämmin, mutta runsassateinen. Kuukauden loppu sitävastoin oli varsin foutainen.

\section{Hernekääriäisen aiheuttamien vahinkojen suuruus.}

Hernekääriäisen esiintymisestä Maatalouskoelaitoksen kasvinjalostusosaston ja sen edeltäjän kokeissa, mainittakoon, että PEsolan $(7,8,9)$ mukaan on hyönteistä tavattu Suomen Kylvösiemen OY:n kasvinjalostuslaitoksen hernekoekentällä Järvenpäässä vv. 1921-23 ja Maatalouskoelaitoksen kasvinjalostusosaston koekentällä Tikkurilassa vv. 1924—27 sekä Jokioisissa vv. 1928—37. Vahinkojen suuruus on vaihdellut eri vuosina, mutta vahingot eivät ole olleet sen laatuiset, että olisivat vaikuttaneet mainittavasti koetulosten käyttöön.

Taulukossa 1 on esitetty kääriäistoukan tuhojen suuruus Jokioisten hernekokeissa vv. 1944-1947. Toukkien aiheuttamien vahinkojen määrä on eri vuosina. vaihdellut huomattavasti. Vuosina 1944 ja 1947 olivat vahingot verraten vähäiset.

$\left.{ }^{1}\right)$ Toukat syövät melkein aina jonkin herneen niin täydellisesti, että sen jätteet puitaessa häviävät. Tästä syystä vioitukset saattavat olla todellisuudessa arvioituja suuremmat. 
Toukkien vioituksesta aiheutunut suoranainen sadonvähennys oli mainittuina vuosina $37-45 \mathrm{~kg} /$ ha eli $2.3-2.5 \%$, vioittuneiden herneiden määrän ollessa 99-100 kg/ha. Vuonna 1945 vahingot olivat jonkinverran suuremmat. Vioituksesta aiheutunut sadonvähennys oli $2.8 \%$ eli $40 \mathrm{~kg} / \mathrm{ha}$ ja vioittuneita herneitä oli sadossa $11.2 \%$ eli $170 \mathrm{~kg} / \mathrm{ha}$. Vuonna 1946 tuhot sitävastoin olivat poikkeuksellisen suuret. Hernesadosta oli noin kolmannes eli $32.8 \%$ vioittunut. Toukkien syönnistä aiheutunut sadonvähennys oli keskimäärin $9.8 \%$ eli n. $130 \mathrm{~kg} / \mathrm{ha}$. Mikäli näin runsas hernekääriäisen esiintyminen on tapahtunut laajemmalla alueella, nousevat satotappiot taloudellisesti varsin merkittäviksi. Siten näyttääkin olleen asian laita. Maatalouskoelaitoksen tuhoeläinosaston havaintojen ja sinne saapuneiden tiedonantojen mukaan oli hernekääriäisen esiintyminen kyseisenä vuonna varsin tuhoisa yli koko herneenviljelysalueemme.

Taulukko 1. Hernekääriäisen aiheuttamien vahinkojen suuruus peltoherneen kenttäkokeissa Jokioisissa vuosina $1944-1947$.

Table 1. The degree of damages in field pea caused by Grapholitha in Jokioinen in the years $1944-1947$

\begin{tabular}{|c|c|c|c|c|c|}
\hline \multirow[t]{2}{*}{$\begin{array}{c}\text { Vuosi } \\
\text { Year }\end{array}$} & \multirow{2}{*}{$\begin{array}{l}\text { Tutkittujen } \\
\text { lajikkeiden } \\
\text { lukumäärä } \\
\text { Number of } \\
\text { varieties } \\
\text { investigated }\end{array}$} & \multicolumn{2}{|c|}{$\begin{array}{c}\text { Vioittuneita herneitä } \\
\text { keskimäärin } \\
\text { Damaged peas on an } \\
\text { average }\end{array}$} & \multicolumn{2}{|c|}{$\begin{array}{c}\text { Sadonvähennys } \\
\text { keskimäärin } \\
\text { The average loss of } \\
\text { pea yield }\end{array}$} \\
\hline & & $\%$ & $\begin{array}{l}\mathrm{kg} / \mathrm{ha} \\
\mathrm{kg} / \mathrm{ha}\end{array}$ & $\%$ & $\begin{array}{l}\mathrm{kg} / \mathrm{ha} \\
\mathrm{kg} / \mathrm{ha}\end{array}$ \\
\hline 1944 & 32 & 6.4 & 100 & 2.3 & 37 \\
\hline 1945 & 21 & 11.2 & 170 & 2.8 & 40 \\
\hline 1946 & 71 & 32.8 & 435 & 9.8 & 130 \\
\hline 1947 & 64 & 5.5 & 99 & 2.5 & 44 \\
\hline
\end{tabular}

\section{Lajike-eroavaisundet.}

Jokioisissa suoritettujen tutkimusten pääasiallisena tarkoituksena oli selvitellä, onko todettavissa eroavaisuuksia eri lajikkeiden alttiudessa hernekääriäisen tuhoille.

Hernekääriäisen aiheuttaman vioituksen suuruutta eri lajikkeilla on tutkinut mm. Nicola isen (6) Saksassa vv. 1926-1927. Näiden tutkimusten mukaan näytti eri lajikkeiden alttius kääriäistuhoille johtuvan pääasiassa eroavaisuuksista aikaisuudessa, kukinta-ajan pituudessa ja kasvutavassa. Mainituissa tutkimuksissa todettiin aikaisin kukkivien lajikkeiden kärsineen toukkain tuhoista vähiten samalla kun erittäin myöhään kukkineilla lajikkeilla vahingot jälleen vähenivät. Kukkimisajan pituus vaikutti vahinkojen suuruuteen siten, että lyhyen ajan kukkivat lajikkeet kärsivät vähiten. Edelleen näyttivät korkeakasvuiset ja rehevät lajikkeet kärsineen tuhoista eniten. Samansuuntaisia tutkimuksia on suoritettu viime aikoina myös Ruotsissa (Bingefors ja WikLund 1). Näissä tutkimuksissa todettiin samoin useimmissa tapauksissa selvä riippuvaisuus vioituksen suuruuden ja lajikkeiden aikaisuuden välillä. Korrelation voimakuus vieläpä suuntakin saattoi kuitenkin 
vaihdella eri koepaikoilla sekä eri vuosina samallakin paikkakunnalla. Myös olivat pienisiemeniset lajikkeet eräissä tapauksissa kärsineet vioituksesta enemmän kuin lajikkeet, joilla oli suuri 1000 siemenen paino. Samoin näytti vioitus ruokaherneillä olevan suurempi kuin kirjavasiemenisillä rehuherneillä.

Jokioisissa suoritetuissa tutkimuksissa havaittiin yksityisinä vuosina verraten selviä eroja lajikkeiden vioittuneisuudessa. Niinpä vuonna 1944 vaihteli vioituksen suuruus $3.9-11.9 \%$ ja vuonna $194622.5-50.0 \%$. Laskettaessa useamman vuoden keskiarvot erot kuitenkin jonkinverran tasoittuivat, koska vioituksen suuruus tietyillä lajikkeilla saattoi eri vuosina vaihdella siten, että niiden keskinäinen järjestys muuttui. Taulukossa 2 on esitetty eräiden jokaisena vuonna mukanaolleiden Jokioisten linjojen vioittuneisuusprosentit eri vuosina sekä neljän vuoden keski-

Taulukko 2, Hernekääriäisen aiheuttaman vioituksen suuruus eräillä lajikkeilla peltoherneen kenttäkokeissa Jokioisissa vv. 1944-1947.

Table 2. The degree of damages by Grapholitha in some pea varieties in Jokioinen in the years $1944-1947$.

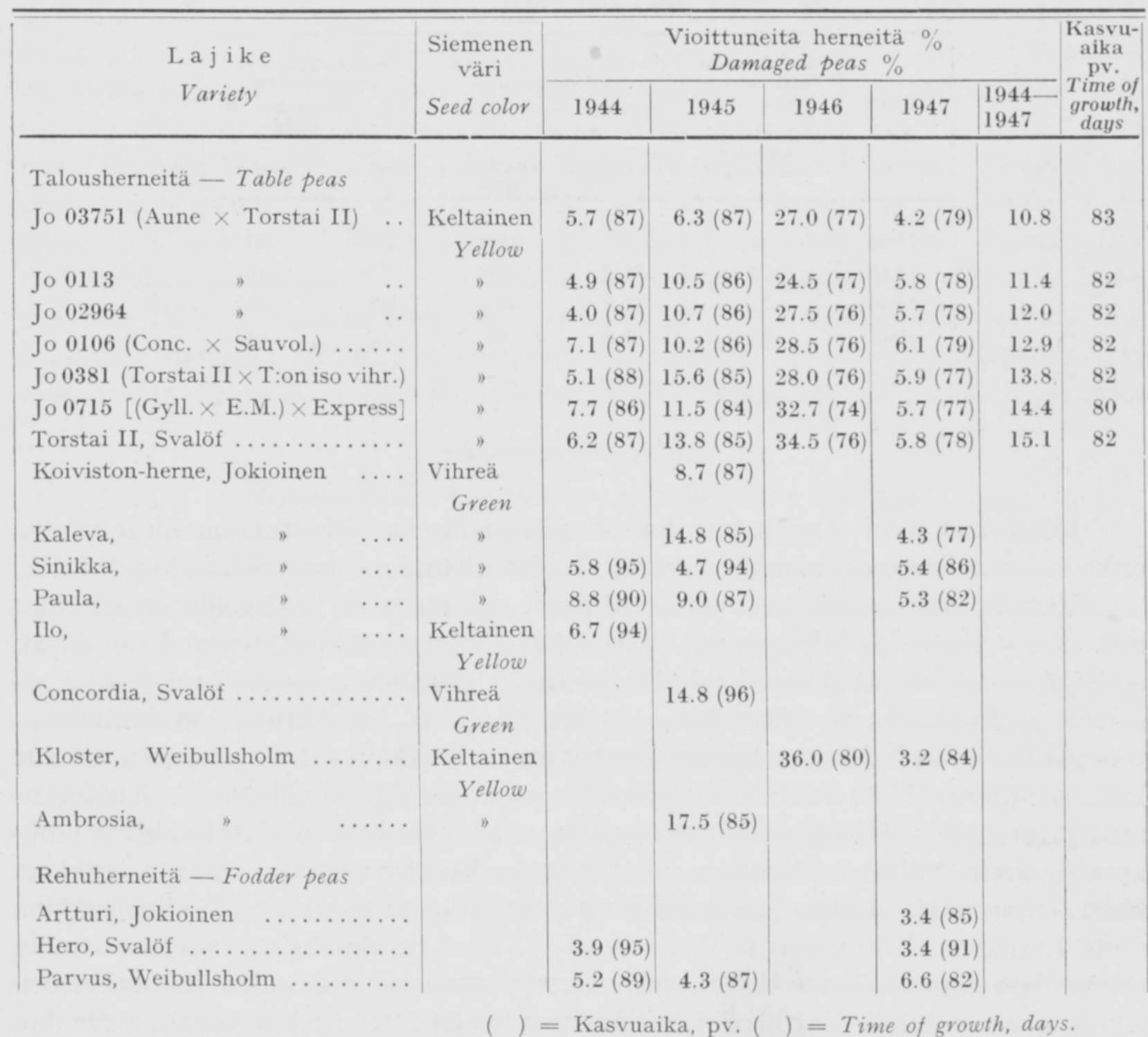




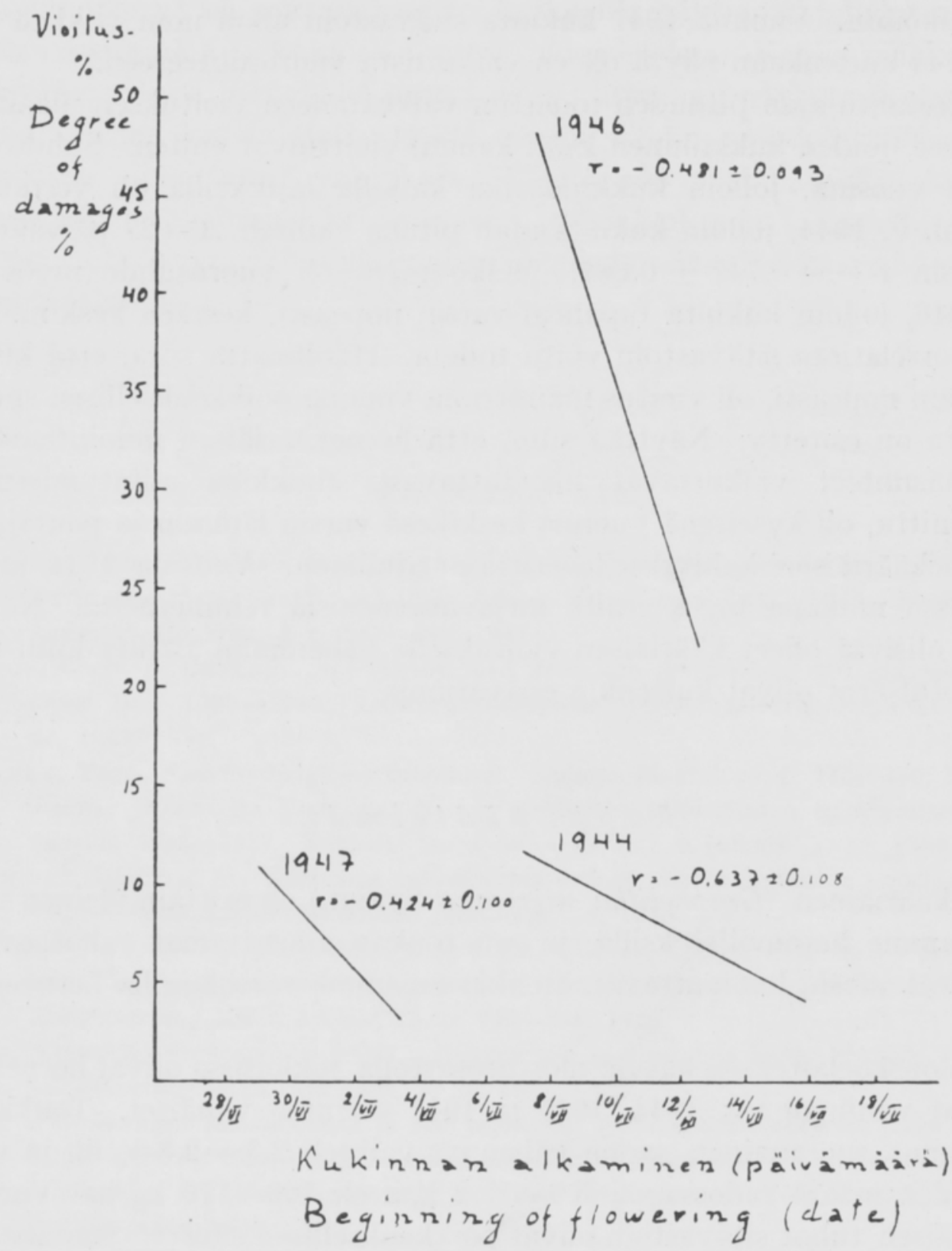

Piirros 1. Hernekääriäisen toukan vioittamien siementen määrän ja kukinnan alkamisajan välinen riippuvaisuus peltoherneen kenttäkokeissa Jokioisissa vuosina 1944,1946 ja 1947.

Fig. 1. The correlation between earliness and degree of damages caused by Grapholitha in Jokioinen in the years 1944, 1946 and 1947.

arvot. Lisäksi on taulukossa esitetty muutamien nimellisten lajikkeiden vioittuneisuus eräinä vuosina.

Vioituksen suuruuden ja kukinnan alkamisajan välillä todettiin tutkimuksissa melko selvä riippuvaisuussuhde eri vuosina. Piirroksessa 1 on esitetty vuorosuhdetta kuvaavat regressiosuorat sekä korrelatiokertoimet vv. 1944, 1946 ja 1947. Aikaiset lajikkeet ovat siis vioittuneet enemmän kuin myöhään kukintansa aloittaneet lajikkeet. Samansuuntainen oli suhde myös v. 1945. Kuten sääsuhteita koskevassa osassa esitettiin, alkoi herneen kukinta vv. 1944 ja 1946 suunnilleen 
samoihin aikoihin. Vuonna 1947 kukinta sitävastoin alkoi noin viikkoa aikaisemmin. Tällä ei kuitenkaan näytä olleen vaikutusta vuorosuhteeseen.

Myös kukinta-ajan pituuden todettiin vaikuttaneen vioituksen määrään siten, että lajikkeet, joiden kukkiminen kesti kauan, vioittuivat eniten. Suhde oli varsin selvä niinä vuosina, jolloin kukkimisaika kaikilla lajikkeilla oli verraten pitkä. Niinpä esim. v. 1944, jolloin kukinta-ajan pituus vaihteli $20-27$ päivään, oli korrelatiokertoin $\mathrm{r}=+0.747 \pm 0.087$. Melko selvä oli vuorosuhde myös v. 1947. Vuonna 1946, jolloin kukinta tapahtui varsin nopeasti, kestäen keskim. 8 päivää, ei selvää korrelatiota sitävastoin voitu todeta. Huolimatta siitä, että kukkiminen tapahtui näin nopeasti, oli vioitus mainittuna vuonna poikkeuksellisen suuri, kuten aikaisemmin on esitetty. Näyttää siltä, että hernekääriäisen muninta-aikana vallitsevat sääsuhteet vaikuttavat huomattavasti toukkien esiintymisrunsauteen. Kuten mainittu, oli kyseisenä vuonna keskikesä varsin lämmin ja poutainen, joten se oli hernekääriäisen kehitykselle erittäin edullinen. Vuosina 1944 ja 1947 oli tutkimuksissa mukana myös eräitä kirjavasiemenisiä rehuherneitä. Näytti siltä, että nämä olisivat olleet kääriäisen vioitukselle vähemmän alttiita kuin talousherneet. Todetut erot olivat kuitenkin epävarmoja.

\section{$L о р р и р \ddot{a} \ddot{a} t$ e $l m \ddot{a} t$.}

Hernekääriäinen (Grapholitha nigricana STEPH.) on erittäin yleinen tuhohyönteinen maamme herneviljelyksillä, ja sen toukan aiheuttamat tuhot ovat useina vuosina olleet varsin huomattavat, etenkin maamme varsinaisella herneen viljelysalueella.

Maatalouskoelaitoksen kasvinjalostusosastolla Jokioisissa olivat hernekääriäisen aiheuttamat vahingot vv. 1944, 1945 ja 1947 verraten vähäiset. Toukkien syönnistä johtunut suoranainen sadon vähennys vaihteli $2.3 .-2.8 \%$ :iin ja vioittuneiden herneiden määrä sadossa oli $5.5-11.2 \%$ :a eli $100-170 \mathrm{~kg} / \mathrm{ha}$. Vuonna 1946 hernekääriäisen tuhot sitävastoin olivat poikkeuksellisen suuret. Suoranainen satotappio oli keskim. $9.8 \%$ eli $130 \mathrm{~kg} / \mathrm{ha}$, vioittuneiden herneiden määrän ollessa $32.8 \%$.

Vioituksen suuruuden ja kukinnan alkamisajan välillä todettiin yksityisinä vuosina melko selvä riippuvaisuussuhde. Aikaisin kukintansa aloittaneet lajikkeet olivat vioittuneet enemmän kuin myöhäiset. Kasvukauden »aikaisuudella» ei näyttänyt olevan vaikutusta riippuvaisuussuhteeseen. Myös kukinta-ajan pituuden havaittiin vaikuttavan vioituksen suuruuteen. Tuhot olivat suurimmat lajikkeilla, joiden kukinta kesti kauan. Selvin oli vuorosuhde niinä vuosina, jolloin kukintaaika yleensä oli suhteellisen pitkä. Kukinta-ajan pituudella ei kuitenkaan näyttänyt olevan ratkaisevaa merkitystä tuhojen suuruuteen. Niinpä vuonna 1946, jolloin kukinta tapahtui verraten nopeasti, vahingot olivat poikkeuksellisen suuret. Sitävastoin näytti hernekääriäisen muninta-aikana vallinneilla sääsuhteilla olevan tärkeä merkitys toukkien esiintymisrunsauteen. Mainittuna vuonna oli herneen kukinta-aika varsin lämmin ja poutainen. 
Vaihtelut vioituksen suuruudessa eri lajikkeilla näyttävät johtuvan pääasiassa lajikkeiden aikaisuuden ja kukinta-ajan pituuden eroista. Koska lajikkeiden varsinaisessa kestävyydessä hernekääriäisen tuhoja vastaan ei näyttänyt olevan mainittavia eroja, lienee kasvinjalostustyöllä varsin vähän mahdollisuuksia vähentää hernekääriäisen aiheuttamia vahinkoja. Päähuomio olisi näinollen kiinnitettävä kemiallisten torjuntakeinojen kehittämiseen tehokkaiksi ja taloudellisesti kannattaviksi. Myös olisi syytä selvitellä mahdollisuuksia vähentää kääriäistuhoja muilla torjuntamenetelmillä.

\section{KIRJALLISUUTTA.}

(1) Bingefors, Sven ja Wiklund, KJell, Ärtvecklaren som skadegörare i ärtförsök vid Sveriges Utsädesförening, Svalöf, och dess filialer under åren 1933-1946. Sveriges Utsädesförenings Tidskrift, 3, p. 280-299, 1947.

(2) Ericsson, Gust. ja Genchel, M., Försök med ärter och ärtblandsäd vid Statens Försöksgård Offer åren 1935-1946. Lantbrukshögskolan Jordbruksförsöksanstalten Meddelande, 21, 1947.

(3) Hukkinen, YrJö, Kasvinviljelyksen tuholaiset. Suomen Maatalous, p. 146-160, 1922.

(4) —- Listo, JаAкко ja Vappula, Niilo, Kertomus tuhoeläinten esiintymisestä Suomessa vuosina 1926-1927. Valtion maatalouskoetoiminnan julkaisuja, 82, 1936.

(5) Linnaniemi, Walter, M., Kertomus tuhoeläinten esiintymisestä Suomessa vuosina 1917-1923. Valtion maatalouskoetoiminnan julkaisuja, 68, 1935.

(6) Nicolaisen, W., Der Erbsenwickler, Grapholitha (Gydia, Laspeyresia) sp., sein Schaden und seine Bekämpfung unter besonderer Berücksichtigung der Anfälligkeit verschiedener Erbsensorten. Kühn Archiv, 19, p. 196-256, 1928.

(7) Pesola, Vilho A., Muutamia tuloksia peltoherneellä suoritetuista kenttäkokeista. Valtion maatalouskoetoiminnan tiedonantoja, 26, 1931.

(8) —- Peltoherneen jalostuksesta ja sen tuloksista Maatalouskoelaitoksen kasvinjalostusosastolla. Referat: Über die Erbsenzüchtung der landwirtschaftlichen Versuchsanstalt Finnlands, Abt. für Pflanzenzüchtung, und ihre Ergebnisse. Valtion Maatalouskoetoiminnan julkaisuja, $66,1935$.

(9) —- Sinikka. Uusi vihreä talousherne. Valtion maatalouskoetoiminnan tiedonantoja, 158, 1939.

(10) SAuli, J. O., Kertomus Hankkijan kasvinjalostuslaitoksen toiminnasta vv. 1921-1924. Keskusosuusliike Hankkijan Siemenjulkaisu, p. 18-19, 1925.

(11) Schwan, Bertil, Ärtvecklaren — ett svåråtkomligt skadedjur på ärter. Växtskyddsnotiser, 1, p. $41-45,1947$.

(12) — - Bekämpningsförsök mot ärtvecklaren, Växtskyddsnotiser, 3, p. 15-16, 1947.

(13) Tullgren, Alb., Landbruksväxternas skadeinsekter, 1937.

(14) Tunblad, Bror, Ärtvecklaren - Ett aktuellt skadejur. Växtskyddsnotiser, 3, p. 33-34, 1937.

(15) Vappula, Nirlo, Tuholaisten esiintyminen v. 1932. Eripainos, Maatalous, 12, 1933, p. 1-6, 1934.

(16) - - Tuholaisten esiintyminen v. 1933. Eripainos, Maatalous, 9, 1935, p. 1-4, 1935.

(17) _- Tuholaisten esiintyminen v. 1937. Valtion maatalouskoetoiminnan julkaisuja, 157, p. $1-10,1939$. 


\title{
S U M M A R Y
}

\section{DAMAGES CAUSED BY GRAPHOLITHA (Grapholitha nigricana STEPH.) TO FIELD PEAS.}

\author{
OIVA INKILÄ.
}

\author{
Central Experiment Station. Division for Plant Breeding. \\ Jokioinen, Finland.
}

The Grapholitha is a most commonly found noxious insect on the pea cultivations in Finland. The damages caused by its caterpillar have been considerable, especially on the regular pea cultivation area.

The table 1. indicates the degree of the damages caused by the Grapholitha in field pea at the experiment field of the Division for Plant Breeding of the Agricultural Experiment Station in Jokioinen in the years 1944-47. The damages in the years 1944, 1945 and 1947 were relatively unimportant. The diminuation of the yield caused by the caterpillar feeding ranged between $2.3-2.8 \%$. In addition are the losses caused by the damaged peas included in the yield to be considered. The amount of damaged peas rose in the years above mentioned to $5.5 .-11.2 \%$ or $100-170 \mathrm{~kg} / \mathrm{ha}$. In 1946 the damages caused by the Grapholitha were exceptionally large. The loss of yield was on an average $9.8 \%$ or $130 \mathrm{~kg} / \mathrm{ha}$. while the amount of the damaged peas was $32.8 \%$.

During the researches a rather clear correlation between the degree of the damages and the earliness of the varieties was found. The damage was larger by the earlier varieties than by the ones with a later flowering time (Fig. 1). The mearliness» of the period of growth seems not to have any influence on the correlation. The length of the time of flowering was found to effect the largeness of the damages so far, that the damage was largest by the varieties with a long flowering time. The correlation was rather clear during the years when the flowering of all the varieties lasted relatively long. Nevertheless the length of the flowering time did not have any decisive significance to the degree of the damages. Thus in 1946, when the flowering time was relatively short, the damages caused by the Grapholitha were exceptionally large. The weather conditions during the flowering of the peas seem instead to have a great effect upon the frequency of appearence of the Grapholitha, because the middle of the summer was rather warm and rainless in the year mentioned.

No noticeable differences seem to be found in the real resistance of the different varietities against the damages caused by the Grapholitha. The alterations in the degree of the damages seem to the most to be caused by the differences in earliness of the varieties and the lenght of the flowering time. 